\title{
Fatigue self-management strategies in cancer survivors: a systematic literature review
}

\author{
Estratégias de autogestão da fadiga nos sobreviventes de cancro: revisão sistemática da literatura \\ Estrategias de autogestión de la fatiga en los sobrevivientes de cáncer: revisión sistemática \\ de la literatura
}

Tiago André dos Santos Martins Peixoto*; Nuno Miguel dos Santos Martins Peixoto**; Célia Samarina Vilaça de Brito Santos ${ }^{* * *}$; Cândida Assunção Santos Pinto****Daisy Maria Rizatto Tronchin ${ }^{* * *}$

\begin{abstract}
Context: In addition to having a significant impact on cancer survivors' quality of life, fatigue is a condition that influences self-management and health-disease transition.

Objectives: This study aims to identify fatigue management strategies used by cancer survivors at the end of treatment through a literature review.

Review method: Systematic literature review based on the Joanna Briggs Institute model. Of the 815 articles found, 8 were included.

Interpretation of results: Strategies related to physical exercise, energy conservation, cancer-related symptom management, self-efficacy perception, coping style, social networks and social support can contribute effectively to reduce and manage fatigue levels, and promote the management of the disease that triggers the adaptation to this new condition. Conclusion: Strategies related to physical exercise, disease-related symptom management, perceived self-efficacy, coping styles and social support are effective for self-managing fatigue in the survival phase.
\end{abstract}

Keywords: fatigue; cancer; survivors, self-care; self-management

\section{Resumo}

Contexto: A fadiga, para além do impacto significativo que tem na qualidade de vida do sobrevivente de cancro, constitui uma condição que influência a autogestão e a transição saúde-doença. Objetivos: Identificar, através de uma revisão da literatura, as estratégias de gestão da fadiga utilizadas pelos sobreviventes de cancro no final dos tratamentos.

Método de revisão: Estudo de revisão sistemática da literatura segundo o modelo da Joanna Briggs Institute. De um total de 815 artigos encontrados, 8 foram incluídos.

Interpretação dos resultados: Estratégias no âmbito do exercício físico, conservação de energia, gestão da sintomatologia associada à doença oncológica, perceção de autoeficácia, estilo de coping, redes sociais e apoio social podem contribuir eficazmente para a redução e controlo dos níveis de fadiga, e promover a gestão da doença que potencia a adaptação à nova condição.

Conclusão: Estratégias no âmbito do exercício físico, gestão da sintomatologia associada à doença, perceção de autoeficácia, estilos de coping utilizados e apoio social são eficazes na autogestão da fadiga na fase de sobrevivência.

Palavras-chave: fadiga, cancro, sobreviventes; autocuidado; autogestão

\footnotetext{
* MSc., Specialist Nurse in Medical-Surgical Nursing, PhD student, Catholic University of Portugal, 4202-401 Porto, Portugal [tiago.andre.peixoto@hotmail.com]. Contribution to the article: literature search; data collection; statistical treatment and assessment; data analysis and discussion; article writing. Address for correspondence: Rua Arquiteto Lobão Vital - Apartado 2511, 4202-401, Porto writing. Address for correspondence: Rua Arquiteto Lobão Vital - Apartado 2511, $202-401$, Porto
** MSc., Specialist Nurse in Medical-Surgical Nursing, PhD student, Catholic University of Portugal, 4202-401 Porto, Portugal [nunomiguelpeixoto@gmail.com]. Contribution to the article: literature search; data collection; statistical treatment and assessment; data analysis and discussion. **** Ph.D., Teacher, Porto Nursing College, 4200-072, Porto, Portugal [celia@esenf.pt]. Contribution to the article: data analysis and discussion.

***** Ph.D., Teacher, Porto Nursing College, 4200-072, Porto, Portugal [candida@esenf.pt]. Contribution to the article: data analysis and discussion.
}

\section{Resumen}

Contexto: La fatiga, además de tener un impacto significativo en la calidad de vida del sobreviviente de cáncer, es un problema que influye en la autogestión y la transición entre la salud y la enfermedad.

Objetivos: Identificar, a través de una revisión de la literatura, las estrategias de gestión de la fatiga utilizadas por los sobrevivientes de cáncer al final del tratamiento.

Método de revisión: Revisión sistemática de la literatura basada en el modelo del Instituto Joanna Briggs. De un total de 815 artículos encontrados se incluyeron 8.

Interpretación de los resultados: Las estrategias dentro del ejercicio físico, la conservación de la energía, la gestión de la sintomatología asociada con la enfermedad oncológica, la percepción de la autoeficacia, el estilo de afrontamiento y las redes sociales, y el apoyo social pueden contribuir eficazmente a reducir y controlar los niveles de fatiga y promover la gestión de la enfermedad, lo cual mejora la adaptación.

Conclusión: Las estrategias dentro del ejercicio físico, la gestión de la sintomatología asociada a la enfermedad, la percepción de la autoeficacia, los estilos de afrontamiento utilizados y el apoyo social son eficaces para autogestionar la fatiga en la fase de supervivencia.

Palabras clave: fatiga, cáncer, sobrevivientes; autocuidado; autogestión

Received for publication: 23.03 .16

Accepted for publication: 15.07 .16 


\section{Introduction}

The evolution of science and technology has transformed the trajectory of several diseases, requiring new therapeutic perspectives. However, the hope of medical advances, which derives primarily from the success in preventing mortality in acute diseases, had to face the emergence of chronic diseases, which created new needs that required a vision beyond a mechanicist approach to health (Pinto, 2007).

Chronic diseases are currently the leading cause of morbidity and mortality worldwide, especially in developed countries. This problem has a clear impact on chronically ill patients and their families, as argued by the World Health Organization (OMS, 2005).

Cancer, which currently meets the requirements for a chronic disease, more than a change in the cell growth and division process, with uncontrolled cell proliferation, integrates the whole idea of discomfort and psychosocial disorganization, resulting from the interaction of the individual with him/herself and the environment (Pais-Ribeiro, 2007).

Nowadays, mainly due to early detection and treatment effectiveness, the course of cancer has changed considerably, and it is no longer a diagnosis of anticipated death. Therefore, surviving cancer has become an experience shared by millions of people.

The International Agency for Research on Cancer (IARC, 2012), through the GLOBOCAN program, has estimated that, in 2012, around 32.5 million people worldwide were alive up to 5 years after a cancer diagnosis. In Portugal, estimates pointed to approximately 134,000 people in the same year (IARC, 2012).

Although the term "cancer survivor" has been used for a decade now, there is no consensus concerning its definition. In this study, we use Feuerstein's concept (2007), in which a cancer survivor to be the person with a cancer diagnosis who completed the primary phase of treatment. This phase, usually known as follow-up, implies a specific management in the health-disease process.

Cancer survivors represent a group of individuals with specific needs and, in accordance with WHO guidelines (Organização Mundial de Saúde, 2008), health professionals should have a comprehensive knowledge of the reality of this new population, as well as of the available scientific evidence. This way they can provide useful professional help, in their area of expertise, to those who have experience cancer, which is "highly destructuring of the self" (Pinto, 2007, p. 31).

However, there is sometimes "a price to be paid for cancer survival" (Pinto, 2007, p. 24), the implications of the actual and potential adverse effects of cancer and its treatments (Schwartz, 2003). Based on this assumption, the patients' cure and ability to resume their previous life is an unattainable goal, thus establishing the chronicity of the cancer disease.

Disease self-management is characterized by engaging in activities aimed at promoting and protecting health, monitoring and managing disease-related signs and symptoms, managing the impact of the disease on functioning, emotions, and interpersonal relationships, as well as adhering to the prescribed treatment (Von Korff, Gruman, Schaefer, Curry, \& Wagner, 1997).

Within the scope of sign and symptom management, cancer survivors need to develop their decisionmaking ability concerning the adjustment of behaviors in case of any change in the status of a symptom or a new disease circumstance, thus incorporating selfknowledge and the technical knowledge required to interpret and act accordingly (Bastos, 2011).

Giving special attention to cancer-related fatigue, which is the most commonly reported symptom in all disease stages, we realize that, despite being a universal experience that usually disappears after rest, this sensation of fatigue usually persists among these people, becoming a chronic and unpleasant condition, and affecting patients' ability to cope with their day-to-day life. Living with fatigue implies a significant physical and emotional burnout that can affect patients' well-being and quality of life and influence their ability to manage their disease (Koornstra, Peters, Donofrio, Borne, \& Jong, 2014; Schjolberg et al., 2014).

According to the National Comprehensive Cancer Network (2014), this type of fatigue is characterized by a subjective sense of tiredness, weakness or lack of energy, which is associated with cancer and its treatments instead of deriving from recent activity, and interferes with the individual's usual functioning. However, no definition has been universally accepted. We performed this systematic literature review (SLR) in six steps: formulation of the research question, definition of inclusion and exclusion criteria for 
studies, search and selection of studies, assessment of the methodological quality of studies, extraction of study data, interpretation and discussion of results. Using the Patient Intervention Comparison and Outcome (PICO) strategy, we formulated the following research question: Which fatigue management strategies used by cancer survivors promote disease self-management?

This study is integrated in the Research Unit of the Porto Nursing College (UNIESEP). Its general objective is to analyze studies on fatigue management through a SLR, and its specific objective is to identify the fatigue management strategies used by cancer survivors at the end of treatment, which are reported in the consulted literature.

\section{Systematic review method}

We conducted a SLR especially because this type of research, in addition to being an essential tool for evidence-based practice, has the main purpose of identifying, assessing and synthesizing the outcomes of relevant scientific studies to answer the research question which results from the interaction of the professional with the clinical practice. This type of research is a valuable resource in the Nursing area because it allows for the collection of relevant information for decision-making, the synthesis of the latest knowledge, and promotes evidence-based care, all these aspects ensuring the optimization of health outcomes.

In order to present the methodological steps in more detail, we designed a research protocol based on the Joanna Briggs Institute guidelines (JBI; 2011). This research protocol was published in the International Prospective Register of Systematic Reviews (PROSPERO) of the Center for Reviews and Dissemination of the University of York, United Kingdom.

In this review, we included studies that: (a) Regarding the type of participants, included individuals aged over 18 years, diagnosed with cancer, regardless of the anatomical site, and in the post-treatment phase; (b) Regarding the type of exposure, addressed cancer-related fatigue management strategies; c) Regarding the type of results, addressed the process of disease self-management [quality of life; well-being; therapeutic regimen management; self- care; self-efficacy; self-concept; self-management; self-regulation; autonomy; health behavior]; (d) Regarding the type of study, were primary studies with an experimental, quasi-experimental, observational-analytical or observational-descriptive design; (e) Regarding the publication date, were published between 1 January 2009 and 31 January 2015; f) Regarding the language, were published in Portuguese and English; g) Regarding accessibility, were available in full text and open access.

\section{Research strategy and identification of studies}

For this study, two researchers of the UNIESEP research project on Chronic Disease Self-Management conducted the search independently in March 2015, using electronic databases.

The researchers used the following expressions: "((("Oncolog* Patient*") OR ("Cancer Surviv*”) OR ("Cancer Patient*") OR ("Malignant* tumor*") OR (MH "Neoplasm") OR ("Cancer*")) AND ((MH "Fatigue") OR ("Cancer fatigue*") OR (MH "Cancer related fatigue") OR ("Fatigue management")) AND ((MH "Quality of Life") OR (MH "Self Care") OR (MH "Self efficacy") OR ("Self-control") OR (MH "Self concept") OR ("Selfregulation") OR ("Patient autonomy*) OR (MH "Patient Compliance") OR (MH "Health behavior") OR ("Attitude to health") OR ("Attitude to illness") OR ("Patient attitude*") OR (MH "Choice behavior") OR (MH "Illness behavior") OR ("Self management") OR (MH "Control (Psychology)")))" in MEDLINE with full text ${ }^{\circledR}$; and "((("Oncolog* Patient") OR (MH "Cancer Survivors") OR (MH "Cancer Patients") OR ("Malignant* tumor") OR (MH "Neoplasms") OR ("Cancer*")) AND ((MH "Fatigue") OR (MH "Cancer fatigue") OR (MH "Fatigue (NANDA)") OR (MH "Fatigue (Saba CCC)") OR ("Fatigue management")) AND ((MH "Quality of Life") OR (MH "Self Care") OR (MH "Self-efficacy") OR (MH "Self-Control (Iowa NOC) (Non-Cinahl)") OR (MH "Self concept") OR (MH "Self regulation") OR (MH "Patient autonomy*") OR (MH "Patient Compliance") OR (MH "Health behavior") OR (MH "Attitude to health") OR (MH "Attitude to illness") OR (MH "Patient attitudes") OR (MH "Behavior")))" in CINAHL plus with full text ${ }^{\circledR}$.

We designed these Boolean expressions to allow for an effective and comprehensive search and to ensure the necessary sensitivity and accuracy required in this type of studies. Thus, we took into account 
the combination of terms indexed in the selected databases, synonym free terms, and the unfolding of the PICO research question, i.e. the terms presented in the group Population $(\mathrm{P})$ were separated by the connector $O R$, as well as in the group Intervention/ Exposure (I) and in the group Outcomes (O). We used the operator $A N D$ between the set of keywords to combine the three groups.

\section{Assessment of the methodological quality of the studies}

Two researchers from the UNIESEP assessed the methodological quality of the studies independently. Prior to the study, all researchers decided that they would only include studies with a high methodological quality, i.e. those that scored 7, 8 or 9 in the MAStARI Critical Appraisal Tools Descriptive/ Case Series Studies (JBI, 2011, p.153) and MAStARI Critical Appraisal Tools Comparable Cohort/Case Control Studies (JBI, 2011, p. 152), and 8, 9 and 10 in the MAStARI Critical Appraisal Tools Randomised Control/Pseudo-randomised trial (JBI, 2011, p. 151).

\section{Data extraction}

Prior to data collection, the researchers developed a table for data extraction and documentation (which included information on each study, namely its title, authors, year, location, methodological orientation, objectives, participants' characteristics, ethical aspects, statistical tests, level of evidence, main results and researchers' observations). This strategy of process systematization, which is recommended by the JBI (2011), aims at ensuring the reproducibility of the review.

To determine the applicability of the instrument used, we conducted a pre-test. Using a randomized study (pilot study), two researchers applied the previously developed instrument, and confirmed its applicability. Two researchers extracted the data independently, between April and June 2015.

\section{Data synthesis}

In order to objectively describe the key results and issues of the studies, we conducted a narrative synthesis of the data using two tables. The researchers worked together to create both tables: one table included sample characteristics, objectives, methodology, results and main conclusions of the studies, and the other one summarized the main results from the studies included in the SLR on cancer-related fatigue and disease management by cancer survivors. Two researchers performed the data synthesis independently, between June and July 2015.

\section{Presentation of results}

As shown in Figure 1, 815 studies were identified: 484 in MEDLINE with full text ${ }^{\circledR}$. (EBSCO host ${ }^{\circledR}$ via ESEP) and 332 in the CINHAL Plus with full text ${ }^{\circledR}$. (EBSCO host ${ }^{\circledR}$ via ESEP), of which 198 were excluded because they were duplicates, 100 were approved in the Relevance Test I (which assessed the potential interest after title and abstract reading), 15 were approved in the Relevance Test II (after full text reading), and 8 were included in the review after methodological quality assessment. It should be noted that seven of the 15 articles submitted to methodological quality assessment scored lower than what had been established in the methodological quality assessment step. 
All articles included in this SLR were written in English, and were published between 2010 and 2013. Two of them were conducted in the United States of America (USA), two in Brazil, one in the United Kingdom, one in Belgium, one in Norway, and, finally, one in South Korea. With regard to the study design, we found five descriptive studies, one randomized controlled study, one observational study, and one case-control study. No less important is the fact that all the included studies met the ethical criteria inherent to the research process: were approved by the respective ethics committees, and all study participants had signed an informed consent.

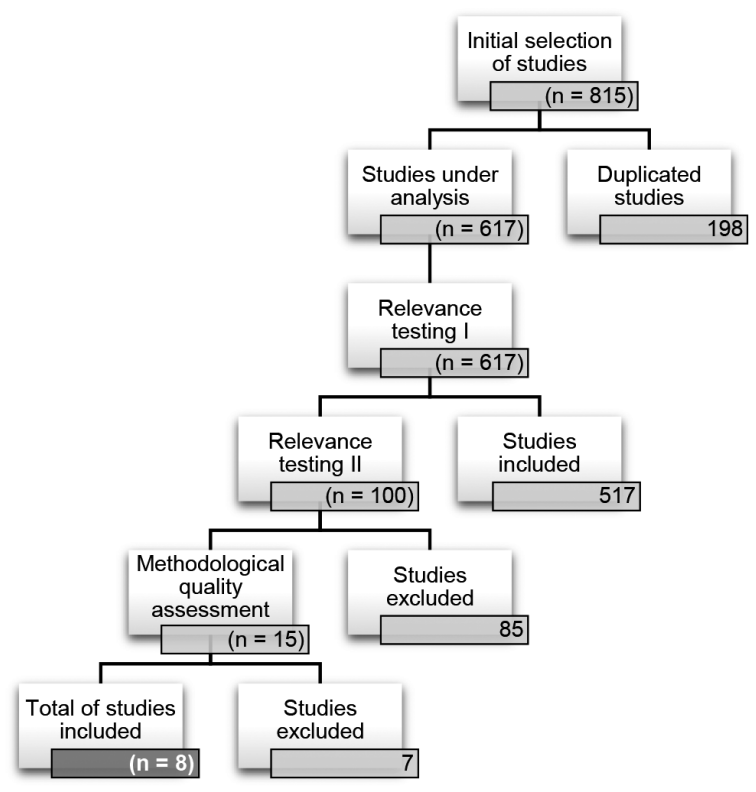

Figure 1. Diagram with the study selection process.

Table 1

Studies included in this SLR, with information on the title and authors of the articles, study objectives, methodological quality score according to the JBI (2011), main results and main limitations

\begin{tabular}{|c|c|c|}
\hline Study / citation & Objective / JBI MQ Score & Main results and main limitations of the studies \\
\hline $\begin{array}{l}\text { E22 - Andrykowski M.A., } \\
\text { Donovan K.A., Laronga C. } \\
\text { \& Jacobsen P.B. (2010). } \\
\text { Prevalence, predictors, } \\
\text { and characteristics of } \\
\text { off-treatment fatigue in } \\
\text { breast cancer survivors. } \\
\text { Cancer, 116(24):5740-8. }\end{array}$ & $\begin{array}{l}\text { To identify the predictors } \\
\text { of fatigue; To identify } \\
\text { differences in physical and } \\
\text { mental health status among } \\
\text { cases and non-cases of } \\
\text { fatigue. } \\
\text { JBI MQ Score - } 7 \text { (MAStARI } \\
\text { critical appraisal tools } \\
\text { Descriptive/Case Series } \\
\text { Studies) }\end{array}$ & $\begin{array}{l}\text { The predictors of fatigue at } 6 \text { and } 42 \text { months after treatment were: } \\
\text { higher Body Mass Index, higher obesity status, greater tendency } \\
\text { to catastrophize about fatigue, less ability to focus, amplification of } \\
\text { physical symptoms, and a lower tendency to adapt to disease symp- } \\
\text { toms; Cancer-related fatigue management should be included in the } \\
\text { end-of-treatment assessment. } \\
\text { Limitations: Sample only included breast cancer survivors. }\end{array}$ \\
\hline $\begin{array}{l}\text { E75 - Blaney, J. M., Lowe- } \\
\text { Strong, A., Rankin-Watt, } \\
\text { J., Campbell, A. \& Gracey, } \\
\text { J. H. (2013). Cancer sur- } \\
\text { vivors' exercise barriers, } \\
\text { facilitators and prefer- } \\
\text { ences in the context of } \\
\text { fatigue, quality of life and } \\
\text { physical activity participa- } \\
\text { tion: a questionnaire-sur- } \\
\text { vey. Psycho-Oncology, 22: } \\
\text { 186-194. }\end{array}$ & $\begin{array}{l}\text { To identify barriers to exer- } \\
\text { cise; To clarify preferences } \\
\text { and identify facilitators of } \\
\text { exercise and quality of life; } \\
\text { To identify cancer survivors' } \\
\text { needs concerning their } \\
\text { participation in physical } \\
\text { activities. } \\
\text { JBI MQ Score - } 7 \text { (MAStARI } \\
\text { critical appraisal tools } \\
\text { Descriptive/Case Series } \\
\text { Studies) }\end{array}$ & $\begin{array}{l}\text { More than half of the interviewed survivors received no advice on } \\
\text { fatigue management from professionals; } \\
\text { About half of the participants were not interested and more than } \\
\text { half did not feel able to participate in a physical exercise program; } \\
\text { The main barriers identified were the disease/other health prob- } \\
\text { lems, joint stiffness, fatigue, pain, and lack of motivation. Physical } \\
\text { exercise could contribute to minimize these barriers. } \\
\text { Limitations: Convenience sample with stage I and II breast cancer } \\
\text { survivors receiving supportive care in charity institutions; The study } \\
\text { did not address the possibility of the participants having comorbidi- } \\
\text { ties with influence on fatigue and quality of life. }\end{array}$ \\
\hline
\end{tabular}


E200 - Kluthcovsky A.C., Urbanetz A.A., Carvalho D.S., Maluf E.M., Sylvestre G.C. \& Hatschbach S.B. (2012). Fatigue after treatment in breast cancer survivors: prevalence, determinants and impact on health-related quality of life. Support Care Cancer, 20(8):1901-9.
To investigate the occurrence of fatigue in diseasefree breast cancer survivors after treatment; To identify variables associated with fatigue; To evaluate the impact of fatigue on quality of life.

JBI MQ Score - 7 (MAStARI

critical appraisal tools Descriptive/Case Series Studies)
More than a third of the sampled women had chemotherapy-related fatigue. Fatigue was significantly associated with women diagnosed with depression, who had higher levels of pain, nausea, vomiting, constipation, dyspnea, insomnia and loss of appetite; Fatigue was also associated with a lower quality of life in all dimensions (European Organization for Research and Treatment of Cancer Core Quality of Life Questionnaire - EORTC QLQ-C30).

Limitations: Sample only included breast cancer survivors from two medical centers; A cross-sectional descriptive study does not allow establishing causal relationships between fatigue and other variables. R., Watthy C., Fontaine C., a rehabilitation program Decoster L., Baillon C., ... on quality of life, fatigue, De Grève J. (2011). Evaluation of a comprehensive rehabilitation program for post-treatment patients with cancer. Oncol Nurs Forum, 38(6):E418-24.

E422 - Phillips S.M. \&

McAuley E. (2013). Physical activity and fatigue in breast cancer survivors: a panel model examining the role of self-efficacy and depression. Cancer Epidemiol Biomarkers Prev, 22(5):773-81 anxiety, depression, and physical condition. critical appraisal tools Comparable Cohort/Case Control Studies)

To longitudinally test a (psychosocial and crossdepression as potential activity and fatigue using tive measures of physical fear of movement, distress, JBI MQ Score - 7 (MAStARI sectional) model examining the role of self-efficacy and mediators between physical both self-report and objecactivity.

JBI MQ Score - 8 (MAStARI critical appraisal tools Descriptive/Case Series Studies)

E477 - Rutskij R., Gaarden To explore the coping T., Bremnes R., Dahl O., Finset A., Fossa SD., ... Dahl AA. (2010). A study of coping in long-term testicular cancer survivors. Psychol Health Med, 15(2):146-58. strategies used by testicular cancer survivors as self-rated by the Brief Approach/ Avoidance Coping Questionnaire (BACQ); JBI MQ Score - 7 (MAStARI critical appraisal tools Descriptive/Case Series Studies)
After the implementation of a rehabilitation program, the participants' quality of life, physical condition, physical function, social function, fatigue, pain, dyspnea, and depression improved significantly. Rehabilitation programs that include both physical and psychoeducational components, as well as individual counselling on effective coping strategies for dealing with cancer-related fatigue and side effects, bring clear benefits.

Limitations: Small sample, only including breast cancer survivors; Lack of a control group (single-arm study); Lack of long-term assessment.

The results of this study provide additional support for the role of self-efficacy, as a modifiable outcome of breast cancer survivors' physical activity and as a potential mediator between physical activity and fatigue. Self-efficacy can influence depression and fatigue, through its impact on the psychological and biological processes. Reduced self-efficacy can restrict the participation in physical activities and undermine any effort to maintain or increase physical activity levels, which may result, in turn, in a gradual loss of interest and skill. This can lead to subsequent increases in depression and fatigue.

Limitations: Homogeneous sample, only including breast cancer survivors; Longitudinal study with a duration of only 6 months.

A significant percentage (16\%) of testicular cancer survivors use mostly avoidance strategies. They have a lower level of education, are usually single, have more side effects and a worse self-perceived health, have more comorbidities and more symptoms, attend more consultations, use analgesics and psychotropic drugs on a regular basis, drink and smoke more. However, most survivors use approach coping strategies; Cancer survivors who use avoidance coping strategies have a significantly lower quality of life, more fatigue (physical and mental), more symptoms, less healthy lifestyles, more depression, more anxiety, and less physical activity.

Limitations: Sample only included testicular cancer survivors; BACQ was only used in a limited number of studies.

E520 - Soares A., Biasoli I., To assess the association of Scheliga A., Baptista R.L., social networks and social Brabo E.P., Morais J.C., ... support with quality of life Spector N. (2013). Asso- and fatigue among longciation of social network term Hodgkin's lymphoma and social support with survivors. health-related quality of JBI MQ Score-7 (MAStARI life and fatigue in long- critical appraisal tools term survivors of Hodgkin Descriptive/Case Series lymphoma. Support Care Studies) Cancer, 21(8):2153-9.
The affective support, informational support, positive interaction, and emotional support dimensions were associated with less fatigue; both social networks and social support were associated with better quality of life and lower fatigue levels among long-term Hodgkin's lymphoma survivors; affective support was associated with almost all dimensions related to quality of life and fatigue; affective support refers to expressions of love and affection, usually provided by friends and family, and might be a particularly valued feature in cancer survivors' interpersonal relationships.

Limitations: Sample only included long-term Hodgkin's lymphoma survivors; The analyzed variables were not assessed before diagnosis, making it impossible to assess the impact of both disease and treatments on these variables. 


\begin{tabular}{|c|c|c|}
\hline $\begin{array}{l}\text { E607 - Yun Y.H., Lee K.S., } \\
\text { Kim Y.W., Park S.Y., Lee } \\
\text { E.S., Noh D.Y., ... Park S. } \\
\text { (2012). Web-based tailored } \\
\text { education program for } \\
\text { disease-free cancer survi- } \\
\text { vors with cancer-related } \\
\text { fatigue: a randomized con- } \\
\text { trolled trial. J Clin Oncol, } \\
\text { 30(12):1296-303. }\end{array}$ & $\begin{array}{l}\text { To determine whether } \\
\text { an Internet-based educa- } \\
\text { tion program is effective } \\
\text { for cancer survivors with } \\
\text { cancer-related fatigue when } \\
\text { compared to usual/routine } \\
\text { care. } \\
\text { JBI MQ Score - } 9 \text { (MAStARI } \\
\text { critical appraisal tools Ran- } \\
\text { domised Control / Pseudo- } \\
\text { randomised trial) }\end{array}$ & $\begin{array}{l}\text { The implementation of a tailored intervention program which cov- } \\
\text { ered six areas: energy conservation, physical activity, nutrition, sleep } \\
\text { hygiene, pain management, and distress management, and an addi- } \\
\text { tional area that allowed participants to evaluate their fatigue status, } \\
\text { improved fatigue, anxiety and quality of life in a more significantly } \\
\text { way than routine care. This program can be an important tool for an } \\
\text { effective self-management of cancer-related fatigue. } \\
\text { Limitations: Computers and mobile phones are not available for the } \\
\text { whole population; Health behaviors were assessed by self-report; } \\
\text { This was not a blind study, so group awareness may have influenced } \\
\text { the results; Use of waiting-list patients as control group; The pro- } \\
\text { gram was not assessed in the long-term. }\end{array}$ \\
\hline
\end{tabular}

Note: Summary of the studies included

\section{Interpretation of results}

Based on the evidence produced by the studies included in this SLR, we observed a general consensus among the various authors concerning fatigue as a symptom $t$ in all disease stages, that may persist for several years (Andrykowski, Donovan, Laronga, \& Jacobsen, 2010; Blaney, Lowe-Strong, Rankin-Walt, \& Campbell, 2013; Kluthcovsky et al., 2012).

In the detailed analysis, we found that the studies included in the SLR cover most of the cancer diseases. Five studies (S22, S200, S422, S477, and S520) analyze the survivors of only one type of cancer, namely breast, lung, and testicular cancer, and Hodgkin's lymphoma. The remaining studies (S75, S232, and S607) include survivors of multiple types of cancer in their samples. In summary, it should be noted that the following factors are significantly associated with higher fatigue levels: poorer quality of life (Kluthcovsky et al., 2012; Yun et al., 2012), greater exacerbation of physical symptoms (Andrykowski et al., 2010; Blaney et al., 2013; Kluthcovsky et al., 2012; Hanssens et al., 2011), an avoidance coping style (Rutskij et al., 2010), chemotherapy (Kluthcovsky et al., 2012), lower participation in physical activity (Blaney et al., 2013), higher Body Mass Index and obesity (Andrykowski et al., 2010), less focus (Andrykowski et al., 2010), changes in the functional role and social function (Hanssens et al., 2011), and higher levels of anxiety (Yun et al., 2012). Focusing on fatigue management strategies used by survivors to promote an effective cancer management, the following themes were identified: physical exercise and energy conservation, symptom management, impact of perceived self-efficacy, coping style, social networks, and social support.

With regard to physical exercise and energy conservation, in the S232 study, Hanssens et al. (2011) concluded that an effective physical exercise program associated with a psychoeducational component and individual counseling, prevents fatigue, reduces its intensity, improves cancer survivors' quality of life and physical condition, and reduces the levels of cancerrelated depression.

In the study conducted by John (2010), lung cancer survivors identified fatigue as "the factor having the most distressing and overwhelming effect on quality of life" (John, 2010, p. 342) and stated that the strategies most often encouraged by their relatives professionals and health professionals, which focused on rest and sleep, were ineffective. In the same study, participants also reported that balancing rest and activity was the main strategy for improving their quality of life and reducing fatigue, as they realized that rest alone was not beneficial.

According to Bower et al. (2014), physical exercise is an essential strategy for reducing the levels of cancerrelated fatigue after treatment. For his purpose, survivors must initiate and maintain adequate levels of physical activity and health professionals must actively encourage survivors to engage in physical activity of moderate intensity after cancer treatment. On the other hand, in the S75 study, Blaney et al. (2013) explain that cancer survivors are a vulnerable group, and that health professionals need to know their exercise preferences, motivations, difficulties and barriers to better adapt the existing programs. If, on the one hand, the exercise barriers identified by cancer survivors related mainly to health or the environment, on the other hand exercise could contribute to minimizing these barriers.

With regard to symptom management, in the S200 study, Kluthcovsky et al. (2012) showed that sociodemographic characteristics, high levels of pain, dyspnea, insomnia, nausea, vomiting, loss of appetite, 
constipation and depression were associated with fatigue, and that the quality of life of survivors with fatigue was significantly poorer in all dimensions when compared to survivors without fatigue.

These results reinforce the need for professionals to use evidence-based recommendations to identify and better understand the predictors of cancerrelated fatigue and, thus, promote the motivation for adherence to behaviors that minimize fatigue after cancer treatment.

In the same line of thought, Bower et al. (2014) affirm the need to address all factors that may worsen fatigue, such as cardiac, endocrine, pulmonary, renal, and neuromuscular disorders, sleep disorders, anemia, arthritis, pain or emotional distress, before a direct approach to this symptom, thereby enhancing the effectiveness of the strategies implemented by survivors to treat or manage fatigue.

With regard to the impact of perceived self-efficacy, in the S422 study, Phillips and McAuley (2013) showed that self-efficacy improved significantly among breast cancer survivors whose physical activity had increased. Women who reported increased self-efficacy showed lower levels of depression and fatigue, confirming the association between higher levels of depression and increased fatigue. The authors found a statistically significant association between changes in physical activity participation and self-efficacy, and between self-efficacy and depression.

Based on these results, we can conclude that physical activity has an indirect influence on fatigue, with efficacy and depression operating as mediating factors. Although several authors have consistently presented physical activity as an effective strategy for reducing fatigue levels, it is clear that few studies have attempted to understand the mechanisms underlying this association. Thus, according to the S422 study, conducted by Phillips and McAuley (2013), it is clear that efficacy can influence depression and fatigue levels through its impact on psychological and biological processes.

Taking into account that self-efficacy has a positive impact, as a mediating agent, on fatigue levels, the strategies used by cancer survivors to enhance perceived self-efficacy have a beneficial effect in reducing fatigue and, consequently, improving cancer management.

On the other hand, as a result of the physical and mental effects of treatment and cancer survivors' cultural expectations, individuals who are dealing with their new identity - as cancer survivors - may experience more pain, fatigue or other symptoms, due to the fact that they recognize themselves as being sick and assume patient behaviors (Marquez, Jerome, McAuley, Snook, \& Canaklisova, 2002).

Therefore, survivors can enter a self-perpetuating cycle, resulting in a decline of their cognitivebehavioral function, i.e. decreased self-efficacy may limit the survivors' participation in physical activities, undermine any effort to maintain or reduce the levels of physical activity, and cause a gradual loss of interest and skills, subsequently leading to increased fatigue and depression levels (Marquez et al., 2002).

With regard to the cancer survivors' coping style, in the S22 study, Andrykowski et al. (2010) showed that a catastrophizing style of coping with fatigue is a predictor of long-term fatigue, and concluded that cognitive factors play an important role in managing fatigue associated with cancer and its treatments.

With regard to the association between coping styles and fatigue levels, Rutskij et al. (2010), in the $\$ 477$ study, concluded that cancer survivors who used avoidance coping strategies reported more treatmentinduced neurotoxic side effects, more comorbidities and somatic and mental disorders, a poorer quality of life, and higher levels of physical and mental fatigue when compared to those who mostly used approach strategies.

This idea reinforces the need for survivors to recognize that approach coping strategies may be more successful than avoidance strategies in managing fatigue and ensuring a greater disease engagement. However, it should be noted that equal strategies may have different results in different people, or even different results in the same person at different moments. Therefore, nurses' intervention should focus on guidance and encouragement to identify the most adequate strategies, adapted to the several contexts and individual idiosyncrasies.

The meta-analysis conducted by Roesch et al. (2005) on coping strategies used by patients with prostate cancer showed that men who used approach coping strategies were healthier, both psychologically and mentally, than men who used approach coping strategies. Moreover, in this study, participants who used avoidance strategies reported low levels of selfesteem, and higher levels of anxiety and depression. Finally, with regard to social networks and social 
support, in the S520 study, Soares et al. (2013) reported that all items related to social networks and social support assessed among Hodgkin's lymphoma survivors were significantly associated with higher levels of quality of life and lower fatigue levels, especially regarding their physical functioning and mental health. More specifically, affective support, information support, positive interactions and emotional support were significantly associated with lower fatigue levels (Soares et al., 2013).

In the same line, the study of Pereira and Botelho (2012) showed that there are multiple studies in the literature in which family and friends are considered as an important source of practical, psychological and emotional support.

In general, cancer survivors who use strategies focused on social support and have a considerable number of friends and relatives usually have better quality of life, and better results in terms of pain management, social functioning, mental health, emotional role, and, consequently, fatigue. In this study (S520), affective support, which refers to expressions of love and affection usually provided by friends and family, may be a particularly valued feature in interpersonal relationships and is associated with almost all dimensions of quality of life and fatigue.

Based on the obtained results, we observed that cancer survivors with better quality of life or lower fatigue levels are more able to maintain relationships with friends and family and, thus, expand their social networks and social support. Therefore, nurses should give special attention to social support and positive interactions while providing care to cancer survivors. In this sense, these professionals have the opportunity to play a significant role in supporting the process of cancer disease management.

This SLR has several limitations that need to be considered in the analysis of the results, such as: a) gray literature was not explored; b) the search was performed in only two databases (MEDLINE with full text ${ }^{\circledR}$ and CINAHL Plus with full text $\left.{ }^{\circledR}\right)$, within a specific timeframe (between 01/01/2009 and 31/01/2015) and with limitations in terms of the language of publication (Portuguese and English); c) the search criterion for the publications to be available in full text and open access; and d) only studies with high methodological quality and level of evidence between I and III according to the JBI criteria (2001) were included.

\section{Conclusion}

This study achieved its initial objective: to analyze the studies on fatigue management strategies used by cancer survivors at end of treatment.

As shown above, cancer disease is considered to be a chronic disease that affects physical, functional, cognitive/psychological, social, economic and spiritual functions, and leads to deep changes in the survivors' everyday life. It requires adaptive responses to these patients' new condition of life, which, per se, justifies supervision by health professionals who must be prepared for this new reality.

With regard to cancer survivors' fatigue, this SLR, despite its limitations, found key evidence-based results to guide nurses' practice and ensure an optimization of health outcomes.

With regard to cancer survivors' fatigue management strategies that promote cancer disease selfmanagement, the themes of physical exercise, cancer-related symptom management, perceived selfefficacy, coping styles, and social networks and social support take on a prominent role.

More specifically, we found that physical exercise (considered in the literature as a central aspect in many chronic diseases) and energy conservation are valid strategies for the effective fatigue management throughout the process of cancer survival. Cancerrelated symptoms, which may persist after end of treatment, namely pain, dyspnea, insomnia, nausea, vomiting, loss of appetite, constipation, and depression, must be addressed. All these symptoms may increase fatigue and compromise post-treatment health and well-being. Moreover, support in empowering for self-management in these processes will promote higher levels of self-efficacy. In turn, the adoption of an approach coping style has proven to be more adaptive, effectively contributing to reduce fatigue levels. Another relevant key variable is social support, and, within it, affective support, information support, positive interactions and emotional support, which were significantly associated with lower fatigue levels.

On the other hand, we found that the self-care strategies developed by cancer survivors, such as balance between rest and activity, energy conservation, lower stress levels, nutrition, healthy behaviors, spirituality, and social support promote an effective fatigue management. 
However, there is a clear need for further research, particularly studies with higher levels of evidence (experimental and quasi-experimental studies). In this Nursing area, few studies exist on cancer survivors' strategies to manage fatigue related to the disease and its treatments, as well as on nursing interventions that promote an effective use of these strategies, contributing to reduce fatigue and facilitate disease management and treatment processes.

Taking into account cancer survivors' increasing needs and the patterns found in this review, there is a pressing need to develop, implement and assess nursing intervention programs that create opportunities to provide a useful professional help at this stage of the disease.

In particular, nurses should focus on: effective ways for the assessment and early detection of fatigue in the survival phase; interventions aimed at improving/ guiding the desired thoughts (effective coping styles); interventions aimed at changing behavioral variables (such as physical activity participation and energy conservation) with an impact on fatigue management; psychosocial and psychoeducational interventions with an impact on fatigue management (such as those addressing self-efficacy and social support/help); and, most importantly, interventions that do not discriminate each cancer survivor's individuality and uniqueness.

Finally, it is clear that chronic diseases are a major challenge for Nursing as a discipline and profession, and, therefore, its interpreters should develop efforts to become valid resources for society in preparing people to effectively face life challenges, especially moments of transition.

\section{References}

Bastos, F. (2011). A pessoa com doença crónica, uma teoria explicativa sobre a problemática da gestão da doença e do regime terapêutico (Tese de doutoramento). Universidade Católica do Porto, Instituto de Ciências da Saúde, Portugal.

Bower, J. E., Bak, K., Berger, A., Breitbart, W., Escalante, C., Ganz, P., ... Jacobsen, P. (2014). Screening, assessment, and management of fatigue in adult survivors of cancer: An American society of clinical oncology clinical practice guideline adaptation. Jornal of Clinical Oncology, 22(17), 1840-1851. doi:10.1200/JCO.2013.53.4495 JCO.2013.53.4495
Feuerstein, M. (2007). Defining cancer survivorship. The Journal of Cancer Survivorship: Research and Practice, 1(1), 5-7. doi:10.1007/s11764-006-0002-x

International Agency for Research on Cancer. (2012). Estimated cancer incidence, mortality and prevalence worldwide in 2012. Retrieved from http://globocan.iarc.fr/Pages/fact_ sheets_population.aspx

Joanna Briggs Institute. (2011) Joanna Briggs Institute Reviewers' Manual: 2011 edition. Retrieved from http://joannabriggs. org/assets/docs/sumari/reviewersmanual-2011.pdf

John, L. D. (2010). Self-care strategies used by patients with lung cancer to promote quality of life. Oncology Nursing Forum, 37(3),339-347. doi:10.1188/10.0NF.339-347

Koornstra, R., Peters, M., Donofrio, S., Borne, B., \& Jong, F. (2014). General and supportive care, management of fatigue in patients with cancer: A practical overview. Cancer Treatment Reviews, 40(6), 791-799. doi:10.1016/j.ctrv.2014.01.004

Marquez, D. X., Jerome, G. J., McAuley, E., Snook, E. M., \& Canaklisova, S. (2002). Self-efficacy manipulation and state anxiety responses to exercise in low active women. Psychology and Health, 17(6),783-791. doi:10.1080/0887044021000054782

National Comprehensive Cancer Network. (2014). NCCN clinical practice guidelines in oncology: Cancerrelated fatigue: Version 1. Retrieved from https:// s3.amazonaws.com/pfizerpro.com/fixtures/oncology/docs/ NCCNFatigueGuidelines.pdf

Organização Mundial de Saúde (2008). Cancer Control: Knowledge Into Action: WHO Guide for Effective Programmes: Module 4: Diagnosis and Treatment. Retrieved from http://www.ncbi. nlm.nih.gov/books/NBK179046/

Organização Mundial de Saúde. (2005). Prevenção de doenças crónicas um investimento vital. Retrieved from http://www. who.int/chp/chronic_disease_report/part1_port.pdf

Pais-Ribeiro, J. (2007). Introdução à psicologia da saúde (2a ed.). Coimbra, Portugal: Quarteto.

Pereira, N. \& Botelho, M. (2012). Experiência Vivida dos Sobreviventes de Cancro do Colón e Reto após Tratamento com Intenção Curativa: Revisão Sistemática da Literatura; Pensar Enfermagem; vol. 16; n ${ }^{0} 1 ; 1^{\circ}$ semestre; 2012;

Pinto, C. (2007). Jovens e adultos sobreviventes de cancro: Variáveis psicossociais associadas à otimização da saúde e qualidade de vida após o cancro (Ph.D. Thesis). Universidade do Porto, Faculdade de Psicologia e Ciências da Educação, Portugal.

Roesch, S. C., Adams, L., Hines, A., Palmores, A., Vyas, P., Tran C., ... Vaughn, A. A. (2005). Coping with prostate cancer: A metaanalytic review. Journal of Behavioral Medicine, 28(3), 281293. doi:10.1007/s10865-005-4664-z 
Schjolberg, T., Dodd, M., Henriksen, N., Asplund, K., Smastuen, M., \& Rustoen, T. (2014). Effects of an educational intervention for managing fatigue in women with early stage breast cancer. European Journal of Oncology Nursing, 18(3), 286-294. doi:10.1016/j.ejon.2014.01.008

Schwartz, C. L. (2003). Health status of childhood cancer survivors: Cure is more than the eradication of cancer.
Journal of the American Medical Association, 290(12),16411643. doi:10.1001/jama.290.12.1641

Von Korff, M., Gruman, J., Schaefer, J., Curry, S. J., \& Wagner, E. H. (1997). Collaborative management of chronic illness. Annals of Internal Medicine, 127(12), 1097-10102. doi:10.7326/0003-4819-127-12-199712150-00008 
